\title{
The use of the Berlin Heart EXCOR in patients with functional single ventricle
}

\author{
Samuel Weinstein, MD, MBA, ${ }^{\mathrm{a}}$ Ricardo Bello, MD, PhD, ${ }^{\mathrm{a}}$ Christian Pizarro, MD, ${ }^{\mathrm{b}}$ \\ Francis Fynn-Thompson, MD, ${ }^{\mathrm{c}}$ James Kirklin, MD, ${ }^{\mathrm{d}}$ Kristine Guleserian, MD, Ronald Woods, MD, \\ Christine Tjossem, BS, ${ }^{\mathrm{g}}$ Robert Kroslowitz, ${ }^{\mathrm{g}}$ Patricia Friedmann, ${ }^{\mathrm{a}}$ and Robert Jaquiss, $\mathrm{MD}^{\mathrm{h}}$
}

\begin{abstract}
Introduction: The frequency and successful use of pediatric ventricular assist devices (VADs) as a bridge to cardiac transplantation have been steadily increasing since 2003, but the experience in patients with complex congenital heart disease has not been well described. Using a large prospectively collected dataset of children supported with the Berlin Heart EXCOR VAD, we have reviewed the experience in children with single ventricular anatomy or physiology (SV), and compared the results with those supported with biventricular circulation (BV) over the same time period.
\end{abstract}

Methods: The EXCOR Investigational Device Exemption study database was retrospectively reviewed. VAD implants under the primary cohort and compassionate use cohort between May 2007 and December 2011 were included in this review.

Results: Twenty-six of 281 patients supported with a VAD were SV. The most common diagnosis was hypoplastic left heart syndrome (15 of 26). Nine patients were supported after neonatal palliative surgery (Blalock-Taussig shunt or Sano), 12 after a superior cavopulmonary connection (SCPC), and 5 after total cavopulmonary connection (TCPC). Two patients received biventricular assist devices, 1 after stage I surgery and 1 after stage II. SV patients were supported for a median time of 10.5 days (range, 1-363 days) versus 39 days (range, $0-435$ days) for $\mathrm{BV}(P=.01)$. The ability to be bridged to transplant or recovery in SV patients is lower than for $\mathrm{BV}$ patients (11 of $26[42.3 \%]$ vs 185 of 255 [72.5\%]; $P=.001)$. Three of 5 patients with TCPC were successfully bridged to transplant and were supported with 1 VAD. Seven of 12 patients with SCPC were bridged to transplant, and only 1 of 9 patients supported after a stage I procedure survived.

Conclusions: The EXCOR Pediatric VAD can provide a bridge to transplant for children with SV anatomy or physiology, albeit less successfully than in children with BV. In this small series, results are better in patients with SCPC and TCPC. VAD support for patients with shunted sources of pulmonary blood flow should be applied with caution. (J Thorac Cardiovasc Surg 2014;147:697-705)

Until recently, options for children listed for cardiac transplantation requiring mechanical circulatory support were limited. Although adolescents can be treated with a variety of adult devices, ${ }^{1-5}$ the only mode of mechanical

\footnotetext{
From Cardiothoracic and Vascular Surgery, ${ }^{\mathrm{a}}$ Montefiore Medical Center, New York, NY; Nemours Cardiac Center, ${ }^{\text {b }}$ Alfred I DuPont Hospital for Children, Wilmington, Del; Cardiac Surgery, ${ }^{\mathrm{c}}$ Boston Childrens Hospital, Boston, Mass; Cardiothoracic Surgery, ${ }^{\mathrm{d}}$ University of Alabama in Birmingham, Birmingham, Ala; Cardiac Surgery, ${ }^{\mathrm{e}}$ Childrens Medical Center Dallas, Dallas, Tex; Cardiothoracic Surgery, ${ }^{\mathrm{f}}$ Childrens Hospital of Wisconsin, Milwaukee, Wis; Berlin Heart Inc, ${ }^{\mathrm{g}}$ The Woodlands, Tex; and Cardiac Surgery, ${ }^{\mathrm{h}}$ Duke University Medical Center, Durham, NC

Disclosures: Christine Tjossem and Robert Kroslowitz are employees of Berlin Heart Inc, The Woodlands, Tex. All other authors have nothing to disclose with regard to commercial support.

Read at the 93rd Annual Meeting of The American Association for Thoracic Surgery, Minneapolis, Minnesota, May 4-8, 2013.

Received for publication May 9, 2013; revisions received Sept 27, 2013; accepted for publication Oct 11, 2013; available ahead of print Dec 2, 2013.

Address for reprints: Samuel Weinstein, MD, MBA, Children's Hospital at Montefiore Medical Center, CT Surgery, 3400 Bainbridge Ave Suite 5B, Bronx, NY 10467 (E-mail: sweinste@montefiore.org).

$0022-5223 / \$ 36.00$

Copyright (c) 2014 by The American Association for Thoracic Surgery

http://dx.doi.org/10.1016/j.jtcvs.2013.10.030
}

circulatory support available for smaller children with cardiac failure was extracorporeal membrane oxygenation (ECMO). The frequency of complications such as bleeding and infection, as well as the inability to extubate or ambulate patients on ECMO makes it an inadequate therapy for patients needing more than a few days of support. ${ }^{6-8}$

Mortality in children treated with ECMO as a bridge to cardiac transplantation is more than $50 \%,,^{8-10}$ and the subset of patients with single ventricular anatomy or physiology (SV) fare the worst. In a multiinstitutional review of more than 750 children supported on ECMO as a bridge to transplant, congenital heart disease (CHD) was the most common indication for listing $(64 \%)$ and, of this group, $30 \%$ were SV (231 patients). Patients with cardiomyopathy had the highest survival to hospital discharge $(63 \%)$, and SV had the lowest survival at 33\%. In addition, children with a diagnosis of SV had the poorest results compared with other diagnoses for death on the waiting list (48\%), death while on ECMO (45\%), and death after transplant and before discharge $(69 \%){ }^{8}$ 


$$
\begin{aligned}
& \text { Abbreviations and Acronyms } \\
& \text { BiVAD = biventricular assist device } \\
& \text { BSA = body surface area } \\
& \text { BT }=\text { Blalock-Taussig } \\
& \mathrm{BV}=2 \text {-ventricle anatomy and physiology } \\
& \mathrm{CHD}=\text { congenital heart disease } \\
& \text { ECMO }=\text { extracorporeal membrane oxygenation } \\
& \text { FDA }=\text { US Food and Drug Administration } \\
& \text { HLHS = hypoplastic left heart syndrome } \\
& \text { IDE = Investigational Device Exemption } \\
& \text { RVAD }=\text { right ventricular assist device } \\
& \text { SV } \quad=1 \text {-ventricle anatomy and physiology } \\
& \mathrm{VAD}=\text { ventricular assist device }
\end{aligned}
$$

In contrast to ECMO support, outcomes for all children receiving a ventricular assist device (VAD) as the bridge modality fare significantly better. ${ }^{11-15}$ In the initial North American experience with the Berlin Heart EXCOR (Berlin Heart Meditechnik GmbH, Berlin, Germany), Morales and colleagues ${ }^{11}$ found $70 \%$ success as a bridge to transplant and $7 \%$ success as a bridge to recovery. In addition, survival after VAD explanation and cardiac transplantation is equivalent to patients receiving a transplant without VAD support. ${ }^{11,13,16,17}$

The primary cohorts in the US Food and Drug Administration (FDA) Investigational Device Exemption (IDE) trial showed $90 \%$ success with the EXCOR Pediatric for bridging to transplant or recovery ${ }^{15}$ but most children receiving devices in the United States were excluded from the primary cohorts, including those patients with complex CHD and SV lesions. Including data from patients treated under the FDA Compassionate Use Regulation, Almond and colleagues ${ }^{17}$ compared overall survival for all patients treated in the United States from May 2007 to December 2010. In this review, survival for 204 patents evaluated at 12 months after treatment with the EXCOR Pediatric VAD was $75 \%$ (64\% transplanted, $6 \%$ recovered, and $5 \%$ were alive with the device in place). Neurologic dysfunction occurred in $29 \%$ of children and was the leading cause of death. Smaller patient size $(<5 \mathrm{~kg})$, biventricular assist device (BiVAD) support and end organ function were associated with early mortality. Less than $10 \%$ of the patients were treated for $\mathrm{SV}$, and a more detailed evaluation of 2-ventricle lesions versus 1-ventricle lesions was not undertaken. ${ }^{17}$

In this article, the initial, multicenter experience using the EXCOR Pediatric to bridge patients with SV physiology is described. In an attempt to define outcomes and practice patterns, data from SV patients treated in the compassionate use cohort are compared with results for patients with 2-ventricle anatomy and physiology (BV).

\section{METHODS}

Twenty-six patients with an anatomic diagnosis of SV CHD who had the EXCOR Pediatric VAD implanted between May 2007 and December 2011 were identified from the EXCOR Pediatric IDE trial database. These patients had the device implanted under the FDA's Compassionate Use Regulation because SV lesions were listed as an exclusion criterion in the primary cohorts of the IDE trial. For reference purposes, we compared these patients with the $255 \mathrm{BV}$ patients supported on EXCOR Pediatric during the same time period. The data analyzed in this review were obtained from the Berlin Heart EXCOR IDE trial database, which was built on the INTERMACS Registry platform.

\section{Statistical Methods}

Data were analyzed using SAS v9.2. Categorical variables are described using frequencies and percentiles. Continuous variables are described using medians and ranges. Statistical comparisons were made using the $\gamma^{2}$ and Fisher exact tests for categorical variables and the nonparametric Kruskal-Wallis test for continuous variables.

Outcome data for competing events are displayed graphically using competing outcomes methodology. Serious adverse events were reported into the database by the participating centers. Only data from the IDE sites were adjudicated before the submission for Humanitarian Device Exemption approval.

\section{RESULTS}

\section{Preimplant Patient Data}

The most frequently occurring diagnosis resulting in cardiac failure requiring placement of a VAD among SV patients was hypoplastic left heart syndrome (HLHS), which occurred in $15(58 \%)$ patients (Table 1). One patient with tricuspid atresia had the EXCOR implanted with a Blalock-Taussig (BT) shunt as the first procedure. All other SV patients had at least 1 operation before VAD implantation; $9(35 \%)$ after stage I palliation, $12(46 \%)$ after stage II palliation, and 5 $(19 \%)$ after stage III palliation. One of the 9 stage I patients with tricuspid atresia had BT shunt placement without neoaortic reconstruction as the first procedure. Two of the 26 patients received a BiVAD, 1 after stage I surgery and 1 after stage II. In both cases, the pulmonary arteries were reconstructed to allow implantation of the right ventricular assist device (RVAD, pulmonary circulation). Systemic support (left VAD, systemic circulation) was maintained from the dominant ventricle to the reconstructed neoaorta. Both patients survived to transplantation. Concomitant procedures performed in 8 of the 26 patients are also described in Table 1.

Patient demographics and clinical characteristics were similar between the SV and BV cohorts (Table 2). Twelve $(46 \%)$ of the SV patients were on ECMO before VAD implantation, similar to the $40 \%$ on ECMO before VAD implantation in the $\mathrm{BV}$ group.

Compared with the BV patients, those with SV had higher bilirubin and hemoglobin levels, and lower antithrombin III, white blood cell count, and albumin levels (Table 3).

\section{Survival}

Successful bridge to cardiac transplantation or recovery using the EXCOR Pediatric was significantly less for the 
TABLE 1. Summary of SV patient data

\begin{tabular}{|c|c|c|}
\hline Variable & Palliation stage & $\begin{array}{c}\text { Result, } \\
\text { n }(\% \text { of } 26)\end{array}$ \\
\hline \multirow{7}{*}{$\begin{array}{l}\text { Primary anatomic } \\
\text { diagnosis }\end{array}$} & Hypoplastic left heart syndrome & $15(57.7)$ \\
\hline & Unbalanced atrioventricular canal & $2(7.7)$ \\
\hline & Tricuspid atresia & $1(3.9)$ \\
\hline & $\begin{array}{l}\text { Pulmonary atresia with intact } \\
\text { ventricular septum }\end{array}$ & $1(3.9)$ \\
\hline & Double inlet left ventricle & $2(7.7)$ \\
\hline & $\begin{array}{l}\text { Ebstein's double outlet } \\
\text { right ventricle }\end{array}$ & $2(7.7)$ \\
\hline & $\begin{array}{l}\text { Transposition, hypoplastic } \\
\text { left ventricle }\end{array}$ & $2(7.7)$ \\
\hline \multirow{3}{*}{$\begin{array}{l}\text { Palliative surgery at } \\
\text { time of EXCOR } \\
\text { implant }\end{array}$} & Stage I & $9(34.6)$ \\
\hline & Stage II & $12(46.1)$ \\
\hline & Stage III & $5(19.2)$ \\
\hline \multirow{3}{*}{$\begin{array}{l}\text { Systemic VAD } \\
\quad(\mathrm{n}=24)\end{array}$} & Stage I & $8(30.8)$ \\
\hline & Stage II & $11(42.3)$ \\
\hline & Stage III & $5(19.2)$ \\
\hline \multirow[t]{3}{*}{ BiVADs $(\mathrm{n}=2)$} & Stage I & $1(3.9)$ \\
\hline & Stage II & $1(3.9)$ \\
\hline & Stage III & $0(0.0)$ \\
\hline \multirow{9}{*}{$\begin{array}{c}\text { Concomitant } \\
\text { surgeries }\end{array}$} & None & $18(69.2)$ \\
\hline & $\begin{array}{l}\text { Atrial septum defect closure } \\
\text { and closure of aortic valve }\end{array}$ & $1(3.9)$ \\
\hline & BT shunt & $1(3.9)$ \\
\hline & Damas-Kaye-Stansel with BT shunt & $1(3.9)$ \\
\hline & Epicardial pacemaker repositioning & $1(3.9)$ \\
\hline & Glenn shunt, BT shunt takedown & $1(3.9)$ \\
\hline & Repair of diaphragmatic hernia & $1(3.9)$ \\
\hline & Repair of inominate artery injury & $1(3.9)$ \\
\hline & Repair of right internal carotid artery & $1(3.9)$ \\
\hline
\end{tabular}

$\overline{V A D}$, Ventricular assist device; $B i V A D$, biventricular assist device; $B T$, Blalock-Taussig.

SV patients compared with the BV patients $(42.3 \%$ vs $73.3 \%, \chi^{2} P=.001$ ) (Table 4). No patients in the SV group were bridged to recovery. Time to death while on VAD support for the SV patients ranged from 0 to 363 days (median 11 days). There were 11 deaths while on EXCOR, and 4 additional deaths in patients who were transitioned to ECMO from the VAD because the device failed to support either the cardiac or pulmonary circulations. Three of these patients died within 30 days on ECMO. A fourth patient survived 9 days on ECMO until receiving a suitable heart, but died 2 weeks after the transplant.

Survival among SV patients differed according to stage of palliation before implant (Table 5). Eight of 9 patients with an EXCOR Pediatric implant after neonatal palliation died, all within 3 weeks of implantation (range, 0-17 days). The only survivor in this review after stage I palliation was a 17-month-old child (Damus-Kaye-Stansel procedure) who had a BT shunt taken down and BiVADs placed after pulmonary artery reconstruction. Seven of 12 patients implanted after stage II palliation were successfully transplanted. One of the VAD survivors with Glenn physiology tolerated the device for 101 days before receiving a heart.
Of the 5 patients supported with EXCOR Pediatric after the Fontan operation, 3 survived to transplantation. The 2 patients who died tolerated support for almost 1 year, and died of multisystem organ failure and hemorrhagic stroke at 362 and 363 days.

The median wait time on VAD support for the 11 patients who survived to transplantation was 52 days (range, 1-229 days). Although there is an early drop in survival among the SV group compared with the BV group (Figure 1, $A$ and $B$ ), 63.6\% (7 of 11) of the SV patients who survived the initial 14 days after implantation were successfully bridged to a transplant with a median wait time of 59 days (range, 22-229 days). Figure 1, $A$ and $B$, shows competing outcomes for the $\mathrm{SV}$ and $\mathrm{BV}$ patients.

\section{Device Details}

Fifty percent of SV patients received an implant with a 25- or 30-mL pump, whereas $38.5 \%$ of SV patients had a $10-\mathrm{mL}$ pump placed. Three patients $(11.5 \%)$, all more than $30 \mathrm{~kg}$, were treated with $60 \mathrm{~mL}$ systemic VADs. These data are similar to the BV group. In-flow cannulae were placed from the dominant systemic ventricular apex as in the BV patients, except for 1 patient with common atrial cannulation, and all outflow cannulae were placed to the ascending aorta. Both patients who had RVADs were cannulated from the right atrium to the pulmonary artery. The systemic VAD stroke rate $(85.0$ vs $70.0 \mathrm{bpm}$, $P<.001)$ and systolic pressure $(200.0$ vs $183 \mathrm{~mm} \mathrm{Hg}$, $P=.01)$ were higher in the SV group compared with BV patients. Pump sizes between both groups were similar and unrelated to mortality. The ratio of pump size to body surface area (BSA) is also similar (SV, 45.4 (interquartile range [IQR], 39.7-53.0); BV, 42.3 [IQR, 34.2-49.7]).

\section{Adverse Events}

Major adverse event rates were similar for the SV and BV groups (Table 6). Among SV patients, the most common adverse events were respiratory failure and bleeding.

The most common causes of death were reported as multisystem organ failure in 5 patients, pulmonary/respiratory failure in 5 patients, cardiac failure in 2 patients, hemorrhage in 2 patients, and hemorrhagic cardiovascular accident in 1 patient.

\section{DISCUSSION}

A pneumatically driven, extracorporeal, pulsatile, mechanical cardiac assist device specifically designed for infants and small children was introduced into clinical practice in 1992. ${ }^{18}$ The Berlin Heart EXCOR Pediatric, built in a variety of pump sizes to accommodate patients from a weight of $3 \mathrm{~kg}$ to adulthood, presented clinicians with a viable option for children with a low BSA who required long-term, mechanical, circulatory assistance. 
TABLE 2. Patient characteristics

\begin{tabular}{|c|c|c|c|c|}
\hline Variable & Summary & 1 Ventricle $(n=26)$ & 2 Ventricles $(\mathbf{n}=\mathbf{2 5 5})$ & $P$ value \\
\hline \multirow[t]{2}{*}{ Age (mo) } & Median [IQR] & $18.8[4.2-46.0]$ & $20.6[6.4-73.1]$ & $.39 *$ \\
\hline & Range & $0.2-173.2$ & $0.4-239.3$ & \\
\hline \multirow[t]{2}{*}{ Weight (kg) } & Median [IQR] & $10.2[5.7-14.0]$ & $10.8[6.8-18.0]$ & $.24 *$ \\
\hline & Range & $2.8-71.0$ & $2.9-60.0$ & \\
\hline \multirow[t]{2}{*}{ Height (cm) } & Median [IQR] & $75.3[58.0-96.0]$ & $82.0[66.0-113.0]$ & $.17 *$ \\
\hline & Range & $48.0-159.0$ & $44.0-171.0$ & \\
\hline \multirow[t]{2}{*}{ Body surface area $\left(\mathrm{m}^{2}\right)$} & Median [IQR] & $0.47[0.31-0.58]$ & $0.50[0.36-0.74]$ & $.23 *$ \\
\hline & Range & $0.19-1.75$ & $0.19-1.67$ & \\
\hline \multicolumn{5}{|l|}{ Body surface area category, $\mathrm{n}(\%)$} \\
\hline $0.19-0.70 \mathrm{~m}^{2}$ & & $23(88.5)$ & $182(71.4)$ & $.06 \dagger$ \\
\hline$>0.71 \mathrm{~m}^{2}$ & & $3(11.5)$ & $73(28.6)$ & \\
\hline \multicolumn{5}{|l|}{ Gender, n $(\%)$} \\
\hline Female & & $12(46.2)$ & $126(49.4)$ & $.75 \dagger$ \\
\hline Male & & $14(53.9)$ & $129(50.6)$ & \\
\hline ECMO preimplant, n (\%) & & $12(46.2)$ & $101(39.6)$ & $.52 \dagger$ \\
\hline \multirow[t]{2}{*}{ Days on ECMO before EXCOR } & Median [IQR] & $6.0[4.5-7.0]$ & $6.0[4.0-10.0]$ & $.53^{*}$ \\
\hline & Range & $2.0-12.0$ & $0.0-38.0$ & \\
\hline
\end{tabular}

$I Q R$, Interquartile range. ${ }^{*}$ Kruskal-Wallis test. $\dagger \chi^{2}$ test.

The availability of pumps with stroke volumes as small as $10 \mathrm{~mL}$, transparent chambers that allowed for direct inspection for thrombus, and the ability to replace pumps at the bedside have led to a considerable increase in the use of this device in the pediatric population since 2000 . $^{6,11,15,17}$ The FDA approved the device in patients less than 21 years of age in December 2011, and at the time of writing, more than 1200 EXCOR Pediatric implants had taken place in more than 30 countries (personal communication from Berlin Heart, Woodlands, TX).

Cardiac transplantation and mechanical support have always played a role in the treatment of CHD, but the small case numbers compared with adults has limited evaluation of the outcomes. Pediatric transplantation represents only about $10 \%$ of total heart transplants performed worldwide, and, of those, only $5 \%$ to $10 \%$ are in patients with SV.
Children with SV treated with mechanical assistance represent an even smaller subset of patients, and the literature on this experience is largely limited to single-center case reports. ${ }^{5,6,20-25}$ Use of VAD support in a patient with a single ventricle was first reported in 2005 in an 25-yearold man after a Fontan operation. The patient was supported for 5 months before successful orthotopic heart transplantation. ${ }^{5}$ Use of the EXCOR Pediatric VAD was first reported in a child with a failing single ventricle in 2006 when it was used to support a 4-year-old girl with HLHS and a Glenn shunt for 28 days. $^{20}$

In 2009, Pearce and colleagues reported the only case in the literature of successful use of a VAD to bridge a child with systemic pulmonary blood flow (BT shunt) to cardiac transplantation. A 15-month-old boy with a double outlet right ventricle, mitral valve atresia, and $\mathrm{D}$ malposition of the great vessels, developed poor systemic ventricular

TABLE 3. Preimplant laboratory variables

\begin{tabular}{|c|c|c|c|}
\hline Laboratory value & $\begin{array}{c}1 \text { Ventricle } \\
(n=26)\end{array}$ & $\begin{array}{l}2 \text { Ventricles } \\
(\mathrm{n}=\mathbf{2 5 5})\end{array}$ & $\begin{array}{c}\text { Kruskal-Wallis } \\
P \text { value }\end{array}$ \\
\hline Bilirubin (reference range, $0.1-1.0 \mathrm{mg} / \mathrm{dL}$ ) & 2.0 [1.1-2.7] & $0.9[0.5-1.9]$ & .009 \\
\hline Aspartate aminotransferase (reference range, $<60 \mathrm{U} / \mathrm{L}$ ) & $74.0[56.0-197.0]$ & $68.0[40.0-152.0]$ & .21 \\
\hline Alanine aminotransferase (reference range, 5-30 U/L) & $43.0[25.0-83.0]$ & $44.0[20.0-115.0]$ & .78 \\
\hline Blood urea nitrogen (reference range, $7-23 \mathrm{mg} / \mathrm{dL}$ ) & $20.5[15.0-38.0]$ & $22.0[14.0-34.5]$ & .63 \\
\hline Creatinine (reference range, $0.16-0.81 \mathrm{mg} / \mathrm{dL}$ ) & $0.5[0.3-0.7]$ & $0.4[0.3-0.6]$ & .75 \\
\hline Hemoglobin (reference range, $11.2-17.5 \mathrm{~g} / \mathrm{dL}$ ) & $12.8[11.9-13.9]$ & $11.5[10.2-12.6]$ & $<.001$ \\
\hline Platelet count (reference range, $150-350$ platelets $\times 10^{3} / \mathrm{mL}$ ) & $147.5[73.0-262.0]$ & $166.0[99.0-303.0]$ & .23 \\
\hline Antithrombin III (reference range, $57 \%-134 \%$ activity) & $59.0[39.0-83.0]$ & $73.0[57.5-87.0]$ & .06 \\
\hline Fibrinogen (reference range, $177-466 \mathrm{mg} / \mathrm{dL}$ ) & $278.0[231.0-375.0]$ & $308.0[227.0-396.0]$ & .76 \\
\hline Plasma-free hemoglobin (reference range, $<10 \mathrm{mg} / \mathrm{dL}$ ) & $27.0[10.0-60.0]$ & $16.0[9.0-31.0]$ & .14 \\
\hline White blood cell count (reference range, $4.3-13.51$ white blood cells $\times 10^{3} / \mathrm{mL}$ ) & $7.9[7.3-10.8]$ & $10.7[8.0-13.8]$ & .02 \\
\hline Albumin (reference range, $2.9-4.7 \mathrm{~g} / \mathrm{dL}$ ) & $3.2[2.7-3.6]$ & $3.4[3.0-3.8]$ & .07 \\
\hline
\end{tabular}

Summary statistics: median [interquartile range]. 
TABLE 4. Support and outcome information

\begin{tabular}{|c|c|c|c|c|}
\hline Variable & Summary & 1 Ventricle $(n=26)$ & 2 Ventricles $(n=255)$ & $P$ value \\
\hline \multirow[t]{2}{*}{ Days of support } & Median [IQR] & $10.5[3-59]$ & $39.0[16-93]$ & $.01 *$ \\
\hline & Range & $0-363$ & $0-435$ & \\
\hline Successful outcome, n (\%) & Transplant or weaned success & $11(42.3)$ & $185(72.5)$ & $.001 \dagger$ \\
\hline \multirow[t]{7}{*}{ Outcome details } & Transplant, n (\%) & $11(42.3)$ & $177(69.4)$ & NA \\
\hline & Weaned for recovery, $\mathrm{n}(\%)$ & $0(0.0)$ & $8(3.1)$ & \\
\hline & Death, n (\%) & $11(42.3)$ & $59(23.1)$ & \\
\hline & Transition to ECMO, death <30 d, n (\%) & $4(15.4)$ & $2(1.2)$ & \\
\hline & Transition to ECMO, transplanted, n (\%) & $0(0.0)$ & $2(1.2)$ & \\
\hline & Transition to ECMO, n (\%) & $0(0.0)$ & $2(1.2)$ & \\
\hline & Weaned because of poor prognosis, $\mathrm{n}(\%)$ & $0(0.0)$ & $5(2.0)$ & \\
\hline
\end{tabular}

$N A$, Not available. *Kruskal-Wallis test. $\dagger \chi^{2}$ test.

function after palliation with pulmonary artery banding and was supported with a 25-mL EXCOR Pediatric VAD. Pulmonary blood flow was initially supplied through the banded pulmonary artery, but persistent hypoxemia necessitated placement of a 5-mm systemic to pulmonary arterial shunt. VAD support was maintained for 7 weeks before successful transplant was performed. ${ }^{23}$ Previous to our report, the largest review of SV patients treated with a VAD was by Van der Pluym and colleagues ${ }^{26}$; this review comprised 10 patients treated since 1988 with 4 different forms of support.

It is likely that the use of mechanical assistance in patients with SV will increase. The Registry of the International Society of Heart and Lung Transplantation report in 2010 found that currently, the most common indication for transplant during infancy is CHD $(60 \%) .{ }^{19}$ The Pediatric Heart Transplant Society found that $36 \%$ of the diagnoses for children listed with CHD were for single ventricle. ${ }^{27}$ Longer waiting times for patients listed, small size, and sensitization from previous operations with bioprosthetic tissue may lead to earlier consideration of mechanical assistance in this population, who often present with rapid circulatory collapse after compensated cardiac failure. 6,28

The small number of patients treated in this review precludes a detailed statistical analysis; however, certain practice patterns and outcomes can begin to be described. Although caution is recommended when considering the use of VAD support in a patient with SV, it is clear from this review that patients can be bridged successfully after a superior caval anastomosis or total cavopulmonary connection. In this first detailed review of the EXCOR
Pediatric experience in patients with SV, we found that patients could be supported until a suitable heart becomes available, but at a lower success rate than seen in patients with 2 ventricles.

The overall success rate of $42 \%$ for bridging SV patients to cardiac transplant in this review, although less than for BV patients, still compares favorably with ECMO therapy. $8,15,29$ Survival for SV patients when ECMO is used as a bridge is $33 \%$; VAD support is capable of providing acceptable mechanical circulatory support for dramatically longer time periods. ${ }^{15}$ This is a critical issue as children with end-stage heart failure face the highest wait list mortality of any patient waiting for a solid-organ transplant. ${ }^{15}$ In addition, survival after VAD support is not different from patients transplanted without a VAD, whereas ECMO support before a cardiac transplant is a risk factor for death. $8,11,13$

However, the superiority of VAD support over ECMO is unclear when considering treating a patient after a stage I procedure with a systemic source of pulmonary blood flow. There were no survivors among patients treated in the neonatal period with VAD support (3 of 9 patients), and all deaths were early ( $\leq 17$ days). Five additional SV patients in this cohort with a VAD and a BT shunt as the source of pulmonary blood flow who were supported at age 2.3 to 7.3 months when they received a VAD also did not survive. The only survivor in this review after stage I palliation was 17 months out from the original surgery, and underwent pulmonary artery reconstruction to allow BiVAD support. There were no survivors among patients treated with VAD support after a stage I procedure when used from the

TABLE 5. Support time by stage of palliation among SV patients

\begin{tabular}{|c|c|c|c|c|c|c|}
\hline Stage of palliation & $\begin{array}{c}\text { Total number } \\
\text { of patients }\end{array}$ & Survivors & $\begin{array}{c}\text { Days EXCOR support } \\
\text { for survivors }\end{array}$ & $\begin{array}{l}\text { Days EXCOR support } \\
\text { for nonsurvivors }\end{array}$ & $\begin{array}{l}\text { Days on EXCOR until } \\
\text { conversion to ECMO }\end{array}$ & $\begin{array}{c}\text { Days after conversion } \\
\text { to ECMO to death }\end{array}$ \\
\hline Stage I & 9 & 1 & 57 & $0,1,1,4,10,11,12,17$ & 1 & 21 (2 wk after transplant) \\
\hline Stage II & 12 & 7 & $5,8,22,52,59,77,101$ & 1,270 & $3,7,7$ & $0,14,30$ \\
\hline Stage III & 5 & 3 & $1,3,229$ & 362,363 & & \\
\hline Total & 26 & 11 & & & & \\
\hline
\end{tabular}



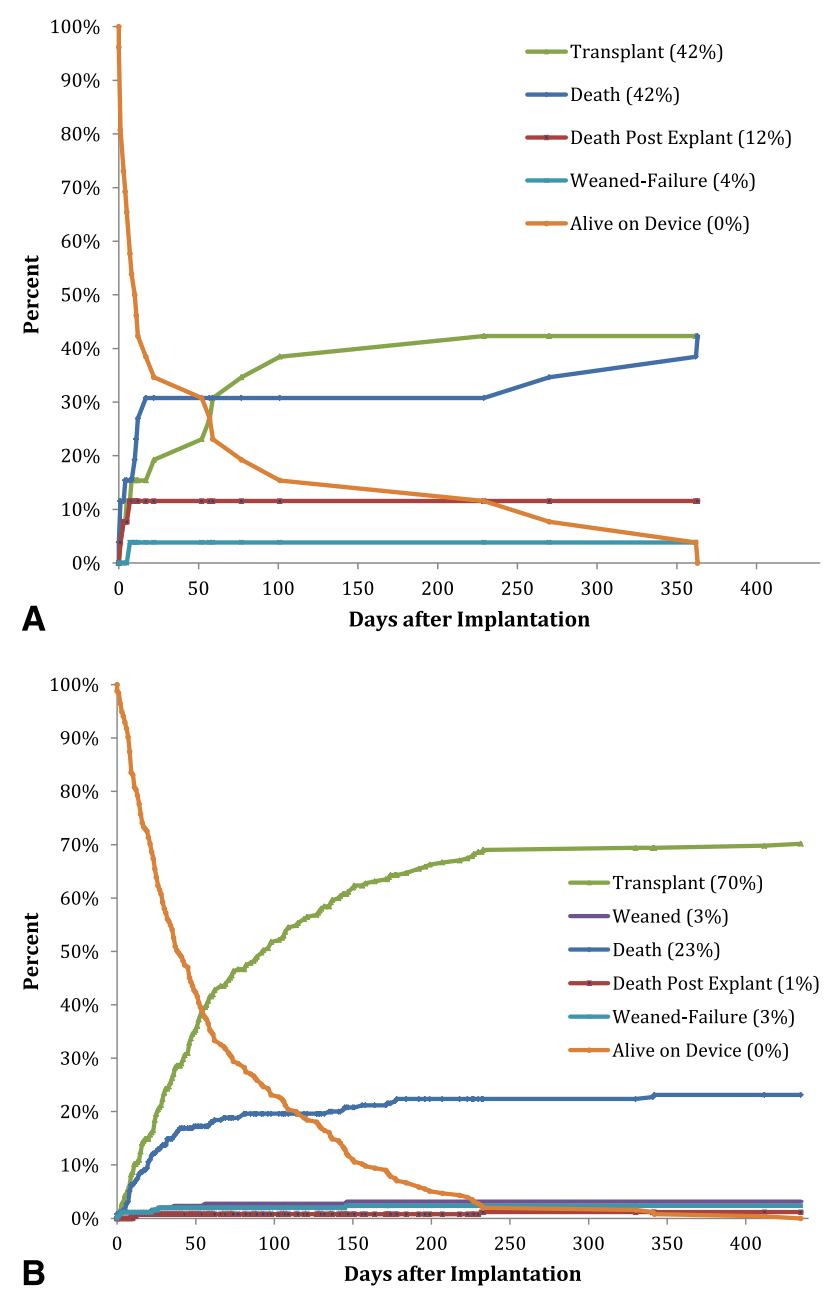

FIGURE 1. A, Competing outcomes for $26 \mathrm{SV}$ patients. B, Competing outcomes for $255 \mathrm{BV}$ patients.

operating room as salvage therapy for failure to wean from bypass, or when a VAD was used for failure to wean from ECMO.

In this review, no SV patient weighing $7.0 \mathrm{~kg}$ or less could be bridged to transplantation. Although younger age and lower BSA are associated with mortality in previous studies, ${ }^{11,17}$ this does not completely explain the dismal outcome for stage I patients. Difficulty in selecting the correct pump size for patients with parallel circulations, extra sources of collateral pulmonary blood flow, and the difficulty in balancing the systemic and pulmonary circulations may all contribute to the unacceptable mortality at this stage. In addition to the challenges of managing shunt physiology on a VAD, immature coagulation systems and technical considerations for small patients, or another as yet unrecognized variable that is a surrogate for size/age may also contribute to the challenges in managing these patients. It may be speculated that as patients can be supported with a single
VAD after a Glenn or Fontan procedure, converting neonates after palliation with a systemic source (arterial or ventricular) of pulmonary blood flow to BiVAD might offer an improvement in outcomes.

In contrast to stage I patients, the data in this report demonstrate that implantation of the EXCOR Pediatric after a Glenn shunt or Fontan operation can be successful, and effective for long-term support. Seven of 12 patients supported with EXCOR Pediatric after a Glenn shunt were bridged to a transplant, the longest for 101 days. Patients with total cavopulmonary connections ( 3 of 5) were successfully supported to transplantation, with 1 of the survivors bridged for 229 days. The 2 patients with total cavopulmonary shunts who did not survive to transplant were supported for362 and 363 days, suggesting that long-term support on Berlin Heart EXCOR can be achieved for SV patients who do not have systemic to pulmonary arterial sources of blood flow. In the overall group, SV patients who could be supported past 14 days had an overall success of bridge to transplantation of $63 \%$, and all but 1 of these patients had a VAD placed after a Glen or Fontan procedure. This is in contrast with the ECMO experience where mortality increases steadily over time. ${ }^{11,17}$

In addition to the significant issues of low BSA, physiology, and increased morbidity of patients who undergo multiple reoperations, there are technical challenges at the time of VAD implantation for SV patients. The apex of the ventricular chamber can be displaced, or the most accessible ventricle may be a smaller chamber with an awkward communication to a larger ventricle. ${ }^{6,26}$ Several surgeons have recommended using transesophageal echocardiography guidance to assist in finding the correct chamber at the time of surgery. Coronary anatomy and other key landmarks at surgery may be obscured by reoperative adhesions. VAD placement after a Fontan operation may require reconstruction of the pulmonary arteries and venous capacitance chamber(s), as well as closure of the fenestration if present. In addition, chronic exposure of most of these patients to cyanosis, hepatic and renal insufficiency, as well as abnormalities in coagulation contribute to a potentially more challenging perioperative period.

The improved success observed recently compared with ECMO has translated to a considerable increase in the use of the EXCOR Pediatric VAD since $2005 .{ }^{17}$ In the setting of improved survival for palliative surgery for all forms of single ventricle and increasing waiting list times for children who develop cardiac failure, VAD therapy may be a more attractive option than ECMO for patients with superior or total cavopulmonary anastomosis.

\section{Study Limitations}

This study has several limitations beyond its description of the initial experience of the EXCOR Pediatric in SV 


\begin{tabular}{|c|c|c|c|c|}
\hline \multirow[b]{2}{*}{$\begin{array}{c}\text { Events occurring while on EXCOR } \\
\text { device support }\end{array}$} & \multicolumn{2}{|c|}{1 Ventricle $(n=26)$} & \multicolumn{2}{|c|}{2 Ventricles $(n=255)$} \\
\hline & $\begin{array}{c}\text { Patient with } \\
\text { event, \% of } 26 \\
(95 \% \text { CI }) \\
\end{array}$ & $\begin{array}{c}\text { Total events } \\
\text { (rate per } 100 \\
\text { patient-days) }\end{array}$ & $\begin{array}{c}\text { Patient with } \\
\text { event, \% of } 255 \\
(95 \% \text { CI }) \\
\end{array}$ & $\begin{array}{c}\text { Total events (rate per } \\
100 \text { patient-days) } \\
\end{array}$ \\
\hline Any serious adverse event & $73.1(56.0,90.1)$ & & $82.8(78.1,87.4)$ & \\
\hline Major bleeding event & $38.5(19.8,57.2)$ & $14(0.85)$ & $44.3(38.2,50.4)$ & $194(1.15)$ \\
\hline Hypertension event & $11.5(-0.7,23.8)$ & $4(0.24)$ & $26.7(21.2,32.1)$ & $73(0.43)$ \\
\hline Major infection event & $23.1(6.9,39.3)$ & $21(1.28)$ & $34.1(28.3,39.9)$ & $239(1.42)$ \\
\hline Neurologic dysfunction & $15.4(1.5,29.3)$ & $4(0.24)$ & $17.3(12.6,21.9)$ & $49(0.29)$ \\
\hline Arterial non-central nervous system thromboembolism & $0.0(0.0,0.0)$ & $0(0.00)$ & $2.7(0.7,4.8)$ & $7(0.04)$ \\
\hline Venous thromboembolism & $0.0(0.0,0.0)$ & $0(0.00)$ & $2.0(0.3,3.7)$ & $5(0.03)$ \\
\hline Renal dysfunction event, acute & $11.5(-0.7,23.8)$ & $3(0.18)$ & $9.8(6.2,13.5)$ & $28(0.17)$ \\
\hline Renal dysfunction event, chronic & $0.0(0.0,0.0)$ & $0(0.00)$ & $0.8(-0.3,1.9)$ & $2(0.01)$ \\
\hline Respiratory failure & $42.3(23.3,61.3)$ & $15(0.92)$ & $27.1(21.6,32.5)$ & $90(0.53)$ \\
\hline Pump change due to thrombus & $26.9(9.9,44.0)$ & $21(1.28)$ & $40.4(34.4,46.4)$ & $194(1.15)$ \\
\hline
\end{tabular}

Total time of support was 1683 days for 1 ventricle and 16,843 days for 2 ventricles.

patients. The small number of cases precludes potential statistical comparisons with non-SV VAD controls. The lack of randomization, although not practical considering the limits of other therapies, means comparing outcomes with historical controls of patients treated with ECMO. In addition, not all serious adverse events were adjudicated because of the inclusion of data from non-IDE trial sites.

\section{CONCLUSIONS}

VADs in SV patients, although less successful than in patients with 2 ventricles, can still be used as a successful bridge to cardiac transplantation. The use of VADs has been more successful in patients with partial or total cavopulmonary shunts than in neonates after a Norwood procedure or with other lesions with shunt-dependent pulmonary blood flow. Whether this is due to patient BSA, age, physiology, or an undiscovered surrogate variable may be uncovered in a larger series. VAD therapy in children with SV after neonatal palliation does not seem to offer any significant advantages over ECMO therapy, and should be applied with caution.

\section{References}

1. Stiller B, Hetzer R, Weng Y, Hummel M, Hennig E, Nagdyman N, et al. Heart transplantation in children after mechanical circulatory support with pulsatile pneumatic assist device. J Heart Lung Transplant. 2003;22:1201-8.

2. Korfer R, El Banayosy A, Arusoglu L, Minami K, Körner MM, Kizner L, et al. Single-center experience with the thoratec ventricular assist device. J Thorac Cardiovasc Surg. 2000;119:596-600.

3. Matsuda H, Taenaka Y, Ohkubo N, Ohtani M, Nishigaki K, Ohtake S, et al. Use of a paracorporeal pneumatic ventricular assist device for postoperative cardiogenic shock in two children with complex cardiac lesions. Artif Organs. 1988;12: 423-30.

4. Tsai FC, Marelli D, Laks H, Moriguchi J, Sopher M, Bresson J, et al. Short-term bridge to heart transplant using the BVS 5000 external ventricular assist device. Am J Transplant. 2002;2:646-51.

5. Newcomb AE, Negri JC, Brizard CP, d'Udekem Y. Successful left ventricular assist device bridge to transplantation after failure of a Fontan revision. J Heart Lung Transplant. 2006;25:365-7.
6. Kirklin JK, Pearce FB, Dabal RJ, Carlo W, McGiffin DC. Cardiac transplantation and mechanical support for functional single ventricle. World J Pediatr Congenit Heart Surg. 2012;3:183-93.

7. Imamura M, Dossey AM, Prodhan P, Schmitz M, Frazier E, Dyamenahalli U, et al. Bridge to cardiac transplant in children: Berlin Heart versus extracorporeal membrane oxygenation. Ann Thorac Surg. 2009;87:1894-901.

8. Almond CS, Singh TP, Gauvreau K, Piercey GE, Fynn-Thompson F, Rycus PT, et al. Extracorporeal membrane oxygenation for bridge to heart transplantation among children in the United States. Circulation. 2011;123: 2975-84.

9. Chan T, Thiagarajan RR, Frank D, Bratton SL. Survival after extracorporeal cardiopulmonary resuscitation in infants and children with heart disease. $J$ Thorac Cardiovasc Surg. 2008;136:984-92.

10. ECMO Registry of the Extracorporeal Life Support Organization (ELSO), July 2009. Ann Arbor, Mich: ELSO; 2009.

11. Morales D, Almond CS, Jaquiss RD, Rosenthal DN, Neftel DC, Massicotte MP et al. Bridging children of all sizes to cardiac transplantation: the initial multicenter North American experience with Berlin Heart EXCOR ventricular assist device. J Heart Lung Transplant. 2011;30:1-8.

12. Stein ML, Robbins R, Sabati AA, Reinhartz O, Chin C, Liu E, et al. Interagency registry for mechanically assisted circulatory support (INTERMACS)-Defined morbidity and mortality associated with pediatric ventricular assist device support at a single US center. Circ Heart Fail. 2010;3:682-8.

13. Blume ED, Naftel DC, Bastardi HJ, Duncan BW, Kirklin JK, Webber SA. Pediatric heart transplant study. Outcomes of children bridged to heart transplantation with ventricular assist devices: a multi-institutional study. Circulation. 2006;113: 2313-9.

14. Arabia FA, Tsau PH, Smith RG, Nolan PE, Paramesh V, Bose RK, et al. Pediatric bridge to heart transplantation: application of the Berlin Heart, Medos and Thoratec ventricular assist devices. J Heart Lung Transplant. 2006;25:16-21.

15. Fraser CD, Jaquiss RD, Rosenthal DN, Humpl T, Canter CE, Blackstone EH, et al. Prospective trial of a pediatric ventricular assist device. $N$ Engl J Med. 2012;367:532-41.

16. Brancaccio G, Filippelli S, Michielon G, Lacobelli R, Alfieri S, Gandolfo F, et al. Ventricular assist devices as a bridge to heart transplantation or as destination therapy in pediatric patients. Transplant Proc. 2012;44:2007-12.

17. Almond CS, Morales DL, Blackstone EH, Turrentine MW, Imamura M Massicotte MP, et al. Berlin Heart EXCOR pediatric ventricular assist device for bridge to heart transplantation in US children. Circulation. 2013;127: $1702-11$.

18. Hetzer R, Alexi-Meskishvvili V, Weng Y, Hubler M, Potapov E, Drews T, et al. Mechanical cardiac support in the young with the Berlin Heart EXCOR pulsatile ventricular assist device: 15 years' experience. Semin Thorac Cardiovasc Surg Pediatr Card Surg Annu. 2006;99-108.

19. Kirk R, Edwards LB, Kucheryavaya AY, Aurora P, Christie JD, Dobbels F, et al. The Registry of the International Society for Heart and Lung Transplantation: thirteenth official pediatric heart transplantation report-2010 J Heart Lung Transplant. 2010;39:1119-28. 
20. Nathan M, Baird C, Fynn-Thompson F, Almond C, Thiagarajan R, Laussen P, et al. Successful implantation of a Berlin Heart biventricular assist device in a failing single ventricle. J Thorac Cardiovasc Surg. 2006;131:1407-8.

21. Chu MWA, Sharma K, Tchervenkov CI, Jutras LF, Lavoie J, Shemie SD, et al. Berlin Heart ventricular assist device in a child with hypoplastic left heart syndrome. Ann Thorac Surg. 2007;83:1179-81.

22. Irving CA, Cassidy JV, Kirk RC, Griselli M, Hasan A, Crossland DS. Successful bridge to transplant with the Berlin Heart after cavopulmonary shunt. J Heart Lung Transplant. 2009;28:399-401.

23. Pearce FB, Kirklin JK, Holman WL, Barrett CS, Romp RL, Lau YR. Successful cardiac transplant after Berlin Heart bridge is a single ventricle heart: use of aortopulmonary shunt as a supplementary source of pulmonary blood flow. J Thorac Cardiovasc Surg. 2009; 137:e40-2

24. Calvaruso DF, Ocello S, Salviato N, Guardi D, Petruccelli DF, Rubino A, et al. Implantation of a Berlin Heart as single ventricle by-pass on Fontan circulation in univentricular heart failure. ASAIO J. 2007;53:e1-2.

25. Mackling T, Shah T, Dimas V, Guleserian K, Sharma M, Forbess J, et al. Management of single-ventricle patients with Berlin Heart EXCOR ventricular assist device: single-center experience. Artif Organs. 2012;36:555-9.

26. VanderPluym CJ, Rebeyka IM, Ross DB, Buchholz H. The use of ventricular assist devices in pediatric patients with univentricular hearts. J Thorac Cardiovasc Surg. 2011;141:588-90.

27. Lamour JM, Kanter KR, Naftel DC, Chrisant MR, Morrow WR, Clemson BS, et al. The effects of age diagnosis and previous surgery in 488 children and adults who undergo heart transplantation for congenital heart disease. J Am Coll Cardiol. 2009;54:160-5.

28. Bernstein D, Naftel D, Chin C, Addonizio LJ, Gamberg P, Blume ED, et al. Pediatric Heart Transplant Study. Outcome of listing for cardiac transplantation for failed Fontan: a multi-institutional study. Circulation. 2006;114:273-80.

29. Rood KL, Teele SA, Barrett CS, Salvin JW, Rycus PT, Fynn-Thompson F, et al. Extracorporeal membrane oxygenation support after the Fontan operation. $J$ Thorac Cardiovasc Surg. 2011;142:504-10.

\section{Discussion}

Dr David L. Morales (Cincinnati, Ohio). Sam, I want to congratulate you on a wonderful presentation and really all the authors on an article that will serve as a great reference to our specialty and growing interest in VAD therapy in children.

Now, the inability to support stage I patients with a VAD really highlights the use of salvage VADs, which are VADs used after an unsuccessful palliation, with these patients subsequently going to ECMO then a VAD. This type of patient has been shown repeatedly in many studies to have extremely poor results regardless of a single-ventricular or a biventricular physiology. Trying to salvage a failed Norwood is just the extreme example of salvage VADs, and it is why their outcomes here are so poor with $89 \%$ mortality.

I have 3 questions regarding this group.

Of the stage I patients who were supported during the neonatal period, how many were on ECMO then a VAD or on a VAD switched to ECMO?

The second question is: What was the time from operation to VAD for the stage I group?

And 3, was any Norwood discharged from the intensive care unit or home before moving to a VAD?

Dr Weinstein. David, thank you very much for your comments and your questions. Your expertise in this field is well recognized, and I have greatly appreciated your advice and personal insight as we have established our own assistance program at my institution.

Four of the 5 neonates who had a VAD implanted were patients who were already on ECMO. There was 1 neonate whose first surgery was an LVAD and a BT shunt, but this patient was converted to ECMO in the operating room for failure to support the cardiac circulation. All stage I patients in this review regardless of age were on ECMO before placement of the device.

Unfortunately, we do not have the information on previous surgeries or discharge data. However, regarding the patients who had a VAD implanted within 30 days of life, I think we can infer that their palliative procedures, ECMO, and subsequent VAD were all in close proximity. As well, there were 3 stage I patients who were aged 7 months, 8 months, and 17 months at the time of VAD implantation, and it may also be inferred that some of these patients were discharged home or at least achieved some form of stability before placement of their mechanical assist device.

Dr Morales. Even with the Glenn cohort, a Glenn who fails in the first few days after surgery is much different than a Glenn who goes home and comes back with a failing systemic ventricle. The Glenn that goes home and returns should be able to be successfully supported, where the one that immediately fails in the intensive care unit again is a salvage VAD and probably would not do well. So with regard to this group, what was the time from Glenn to VAD for survivors and nonsurvivors?

And 2, did any of the Glenns go home and return for their VAD, and what was their survival compared with those who never left the hospital?

Dr Weinstein. The Berlin Heart database does not have the data on the timing of any procedures performed before the VAD, but the median age of patients undergoing a VAD implant with Glenn shunt physiology was 2 years, and the oldest patient was 13 years. For similar reasons, I assume several of these patients left the hospital, some for perhaps a significant amount of time. So I think that these data support your presumption that the further out you are from any one of your staged palliations, the more likely you are to survive VAD support.

Dr Morales. And just a final comment. Single-ventricle patients are not different than other congenital patients and a failed palliation supported with a VAD will probably result in poor outcomes; however, the single-ventricle physiology just emphasizes this point.

Having said that, VAD therapy in patients who have systemicto-pulmonary shunt and the late-failing Fontan are unique challenges compared with other single-ventricle patients and ones that we will have to continue to investigate I think. But again, you and your authors have given us a great first step with this article. Thank you.

Dr Christopher A. Caldarone (Toronto, Ontario, Canada). Sam, could you comment a little bit on the overall interpretation of your presentation. I mean, it sounds quite dismal in terms of the concept of mechanical support for the failing single ventricle, but that may be a function of some immutable bit of physiology among single-ventricle patients or it may be that we are just too slow to pull the trigger and go to mechanical support. This is a decision we wrestle with constantly. And can you get any insights from the data that you have here?

Dr Weinstein. I think that success is related as much to age as to stage, and I am not sure which variable is the most important. There were 4 patients who were supported with ECMO before VAD implantation who were not shunted patients, 2 Glenns and 2 Fontans. And 3 of those 4 survived. So I think that for neonates and for shunted patients, and as a salvage procedure, it 
does not seem, from this small group only, that it would be warranted. But I do think for older patients, patients that may be further out from stage II or stage III palliation, it is very much worth considering.

Dr Pedro J. del Nido (Boston, Mass). Do you have any information about, especially focusing on the neonatal group, the need for CPR before any mechanical support, either ECMO or if you went straight to a VAD? Do you have any data about that group? Because I would think that need for CPR may be the trigger point for you to decide whether you are going to put a child on this long-term assist or not.

Dr Weinstein. That is an excellent point. Unfortunately, the information about CPR or other status before ECMO implant is anecdotal. 